\title{
BC Supreme Court begins hearing doctors' class-action lawsuit
}

$\mathrm{M}$ adam Justice Elaine Adair of the BC Supreme Court has begun hearing a class-action lawsuit involving 7000 doctors, including the province's former health minister, who are trying to recover fees they claim British Columbia owes them.

Dr. James Halvorson, the lead plaintiff in the lawsuit, is suing the Medical Services Commission over fees the doctors say they should have received from 1992 to 1996 , when the province cancelled the enrolment of $\mathrm{BC}$ residents who did not pay Medical Service Plan premiums.

The problems for physicians arose when they tried to bill the province after treating patients whose membership in the Medical Service Plan had been cancelled, unbeknownst to the doctors, who had no way of checking the patients' status. The doctors' payment claims were rejected.

Halvorson, an emergency physician from Duncan, British Columbia, says emergency doctors were hit hardest, because patients without coverage were often referred to them. As a policy, they did not turn emergency cases away.

Halvorson says he alone is owed upwards of $\$ 100000$.

The lawsuit, which Adair began hearing Apr. 22 to 24, seeks about $\$ 100$ million in unpaid fees for close to 400000 uninsured patients.

"The medical care for all of those people was strictly on the backs of the medical physicians involved," says Halvorson. "It was not an insignificant problem."

During the period that the lawsuit covered, BC collected transfer payments from the federal government to

cover the cost of uninsured patients, which Halvorson says the province did not pass on to the physicians.

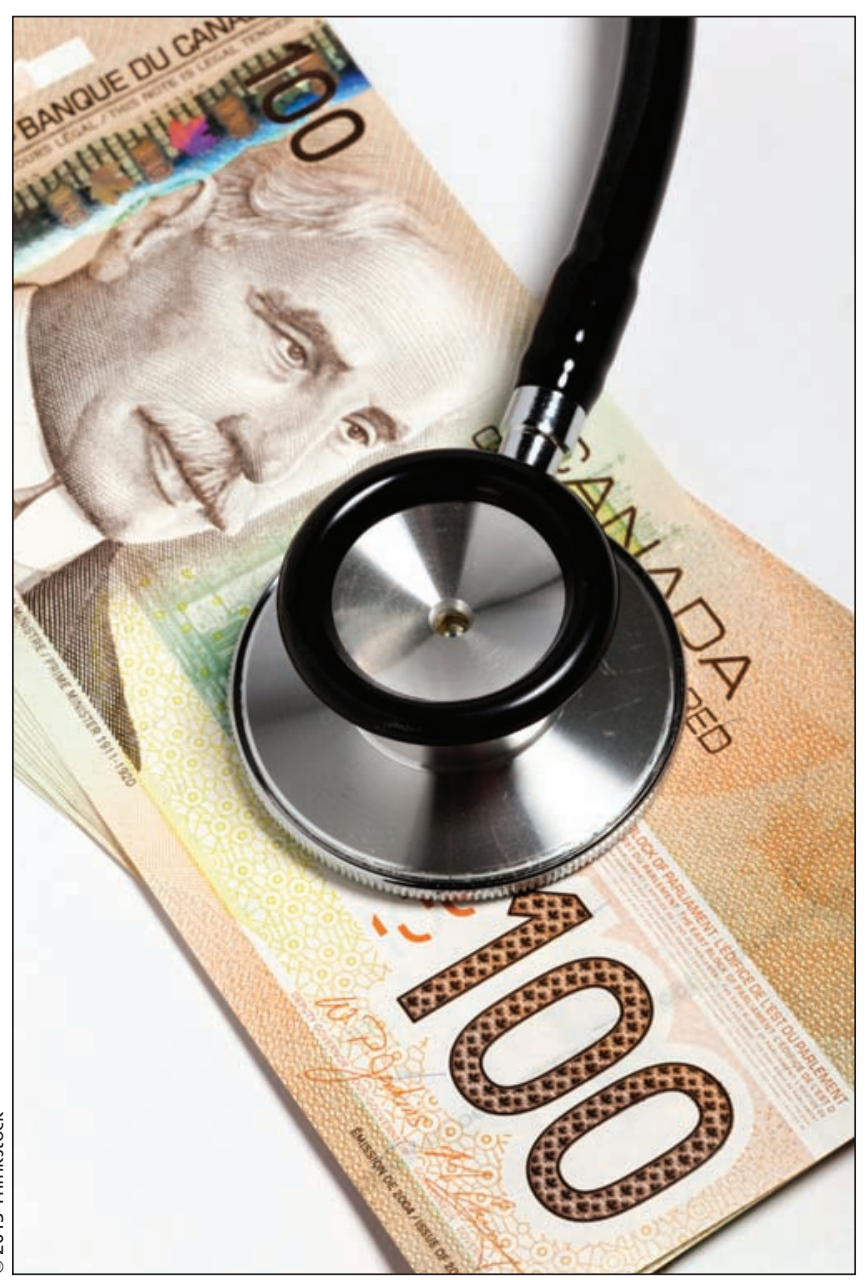

BC doctors are suing the province for an estimated $\$ 100$ million in unpaid fees for close to $\mathbf{4 0 0} 000$ uninsured patients.
The government contends it had the legal authority to cut residents from the health insurance plan if they had failed to pay their premiums.

The cost of premiums varies in British Columbia, from \$64 a month for an individual to $\$ 128$ for a family of three. Government subsidies of between $20 \%$ and $100 \%$ are available to individuals earning an annual income of less than $\$ 30000$.
Halvorson initially brought suit in October 1998, but it has taken until now, through a series of decisions and appeals, to get certified as a class action and to finally get a hearing in the province's top court.

"We had a lot of procedural roadblocks in the way," says Arthur Grant, the lawyer representing the plaintiffs. He hopes the suit will be resolved by fall.

The class action applies, by court order, to all doctors practising in $\mathrm{BC}$ between July 23, 1992, and Apr. 30, 1996 — including Dr. Margaret MacDiarmid, a family doctor who served as BC's health minister from the fall of 2012 until her defeat in the provincial election May 14. Facing a potential conflict of interest, MacDiarmid had written to Adair asking to be excluded from the lawsuit. It is unclear whether she will still opt out now that her conflict of interest no longer exists.

Today, the Medical Service Plan system is computerized, so doctors can check a patient's status before they treat them. In 2012, nearly 1 million British Columbians received premium assistance, and more than 800000 of them did not pay any premiums.

"I think we would be better served by not having a premium-based system," says Halvorson, who feels health care should be universal, and paid for out of general funds.

"It's a mindset that I would love to see changed," he says. — Jasmine Williams, Ottawa, Ont.

CMAJ 2013. DOI:10.1503/cmaj.109-4511 